\title{
Integrated Solar Combined Cycle Power Plants: Paving the Way for Thermal Solar
}

\author{
Bandar Jubran Alqahtani ${ }^{1}$ and Dalia Patiño-Echeverri ${ }^{1 *}$ \\ 1. Duke University. Nicholas School of the Environment. \\ *Corresponding author: dalia.patino@duke.edu, ph: 919 358-0858, fax: 919.684 .8741
}

\begin{abstract}
Integrated Solar Combined Cycle Power Plants (ISCCs), composed of a Concentrated Solar Power (CSP) plant and a natural gas-fired Combined Cycle (NGCC) power plant, have been recently introduced in the power generation sector as a technology with the potential to simultaneously reduce fossil fuel usage and the costs of integrating solar power in an electricity system. This study quantifies the economic and environmental benefits of an ISCC power plant relative to a stand-alone CSP with energy storage, and a NGCC plant. The corresponding levelized cost of electricity (LCOE) and the cost of carbon abatement (CoA) are estimated by simulating hourly operations for five U.S. locations with different solar resources and ambient temperature, under varying assumptions regarding natural gas prices, tax incentives, capacity factors, and capital costs. Results show that integrating the CSP into an ISCC reduces the LCOE of solar-generated electricity by $35-40 \%$ relative to a stand-alone CSP plant, and provides the additional benefit of dispatchability. An ISCC also outperforms a CSP with energy storage in terms of LCOE and CoA. The current LCOE of an ISCC is lower than that of a stand-alone NGCC when natural gas prices reach 13.5 \$/MMBtu, while its CoA is lower at a fuel price of 8.5 \$MMBtu. Although, under low to moderate natural gas price conditions, a NGCC generates electricity and abates carbon emissions at a lower cost than an ISCC; small changes in the capacity factor of an ISCC relative to the NGCC, or capital cost reductions for the CSP components significantly tilt the balance in the ISCC's favor. Hence, this technology should be seriously considered as a cost-effective baseload electricity generation alternative to speed up the transition to sustainable energy systems.
\end{abstract}

\section{Introduction}

The Integrated Solar Combined Cycle Power Plant (ISCC) has been introduced in the power generation sector as a technology with the potential to help reduce the costs of solar energy for electricity generation. An ISCC power plant combines a Concentrated Solar Power (CSP) plant and a Natural Gas-Fired Combined Cycle (NGCC) power plant. The CSP energy is used to either produce additional steam for use in the NGCC's steam turbine to generate electricity [1], or to heat the compressed air in the gas turbine before entering the combustion chamber [2]. ISCC plants effectively integrate solar power into the grid by circumventing the non-dispatchability of the CSP [3] and reducing operating and capital costs, with the possibility of increased operational flexibility when compared to a standalone NGCC [4].

The concept of the ISCC as a parabolic trough solar plant integrated with modern combined cycle power plants was initially proposed in the early 1990s by Luz Solar International, the builders of the SEGS trough plants in California [1, 5]. The first plant materializing this concept was the Archimede Project in Sicily Italy, which consists of two $380 \mathrm{MWe}$ gas-fired combined cycle power plants and a 5 MWe parabolic trough solar field that uses molten salts as heat transfer fluid (HTF) [5]. As of 2015, there are at least 157MW of thermal solar plants integrated with a natural gas combined cycle plant, including the 75MW Martin Next Generation Solar Energy Center in Indiantown Florida, 20MW ISCC Ain Beni Mathar in Morocco, 20MW ISCC Hassi R'me in Algeria, 20MW ISCC Kuraymat in Egypt and the 17MW ISCC Yazd in Iran. [6-9]

Previous literature offers valuable insights into the advantages of the ISCC technology and the best configurations, but the need for an analysis making use of the most recent data and offering comparative information with similar baseload electricity generation alternatives persists. Most previous studies evaluate the technical and economic advantages of the ISCC, explore different solar thermal technologies, and discuss alternative setups to optimize performance. J.H. 
Peterseim et al. [6] evaluated all suitable CSPs technologies for integration with Rankine cycle power plants. The study concluded that: a) line focusing systems such as Fresnel and parabolic trough are ideal for integration of lower temperature steam $\left(<400^{\circ} \mathrm{C}\right)$, b) Fresnel systems are the most efficient for medium temperatures $\left(380^{\circ} \mathrm{C}\right.$ to $\left.450^{\circ} \mathrm{C}\right)$, and c) Direct Steam Generation solar towers are the best for higher temperatures $\left(>450^{\circ} \mathrm{C}\right)$. Kelly et al. [10] studied two integrated plant designs using Gate Cycle modeling software and concluded that: a) annual solar contributions of up to 12 percent in an ISCC offer economic advantages over conventional solar-only parabolic trough power plants, and b) that the most efficient use of solar thermal energy is the production of high-pressure saturated steam for addition to the heat recovery steam generator. Rovira et al. [11] assessed a number of ISCC configurations with solar parabolic trough collectors and found that the direct steam generation (DSG) configuration is the best choice for solar energy integration although there may be problems with a) the control of the solar field during solar radiation transients, b) the two-phase flow inside the receiver tubes, and c) temperature gradients in the receiver tubes. Montes et al., [12] and Nezammahalleh et al., [13] conducted techno-economic assessments of an ISCC using Direct Steam Generation (DSG) in parabolic trough collectors demonstrating the importance of optimizing the solar field size as a function of the power cycle capacity (i.e. the solar multiple) to improve daily operations, annual performance, and costs. Yuanyuan et al., [14] proposed and investigated a new ISCC system with a two-stage solar DSG input to increase the solar share. Compared with a one-stage ISCC plant, the two-stage ISCC presented better performance and increased net solar-to-electricity efficiency (to up to 30\%). Recently, Mokheimer et al., [15] investigated the technical and economic feasibility of integrating a Parabolic Trough Collector (PTC) system with a gas turbine cogeneration system considering different generating capacities of gas turbine and areas of PTCs. They concluded that hybrid systems with gas turbine generating capacities less than $110 \mathrm{MWe}$ result in a negligible increase in the LCOE but are more economically attractive compared to cogeneration coupled with a $\mathrm{CO}_{2}$ capturing technology. O. Behar et al. [5] conducted a worldwide technical review of ISCC plants and the status of related research development and deployment (RD\&D), and concluded that there has been an exponential increase in the RD\&D especially on the DSG-ISCC technology which may offer better performance than the widely installed parabolic trough-ISCC plants.

Other studies discuss operational alternatives and present costs and benefits for extant ISCC plants in Egypt [7], Spain [8], and Algeria [9]. J. Antonanzas et al. [8] analyzed the overall potential for solar thermal integration in 51 NGCC plants in mainland Spain under different operating scenarios concluding that the ISCC technology offers enormous opportunity to improve yield and efficiency in peak periods and to reduce $\mathrm{CO}_{2}$ emissions. The study analyzed the penalty of solar dumping when ISCC is operated in solar boosting mode and also gas turbine efficiency when ISCC is operated in solar dispatching mode. Also, J. Antonanzas et al. [16] looked at the feasibility of integrating CSP parabolic trough systems with 21 Algerian open cycle gas turbines and combined cycle gas turbines concluding that a yield increase of $24.9 \mathrm{GW} \mathrm{h} /$ year and $\mathrm{CO}_{2}$ emission savings of $9.91 \mathrm{kton} /$ year are feasible with solar field sizes ranging from 30 to 37 loops in combined cycle centrals. For open cycle gas turbines, a solar potential of $1085.7 \mathrm{GW}$ h/year and $\mathrm{CO}_{2}$ emission savings of $652.1 \mathrm{kton} / \mathrm{year}$ were found possible with annual solar electricity shares in the range of 3-4\%.

Previous studies conducted a static analysis of the performance of ISCC plants without accounting for the temporal variation of solar energy production and other factors likely to significantly affect the economics of this technology. One exception is a study conducted by J. Dersch et al. [17] which compares the costs and $\mathrm{CO}_{2}$ emissions of ISCC plants to both CSP and conventional combined cycle (CC) power plants, assuming different configurations and operating modes. By using hourly data of solar radiation and ambient conditions for a typical meteorological year in both Barstow, California and Tabernas, Spain, the authors conclude that a) for the same location and operating conditions, ISCC plants have lower $\mathrm{CO}_{2}$ emissions than $\mathrm{CC}$ plants, and b) for baseload (i.e. 24 hour operations), ISCC plants have lower costs and $\mathrm{CO}_{2}$ emissions than CSP plants with supplementary firing. The other exception to the common ISCC static analyses is the work of Moore and Apt [18] who simulated one year of hourly operations of an ISCC located in Phoenix Arizona, receiving prices that vary in the same way as the median of all nodal hourly prices in California ISO. The plant is run to maximize hourly marginal profits so for every hour any of three situations occurs: 1) the plant runs only with natural gas (i.e. "at base load"); 2) the plant operates as an ISCC with both gas and whatever solar energy is available (i.e. "with duct firing"); or 3) the plant does not run at all. A parametric analysis that varies natural gas prices between 2 and 12 \$/MMBTU and adjusts hourly electricity prices to reach annual averages between 35 and 85 (\$MWh), results in ISCC 
capacity factors of 3\%- 90\% and unsubsidized Levelized Cost of Electricity (LCOE) from the solar portion of the ISCC in the range $170-380(\$ / \mathrm{MWh})$.

In the vein of [17] and [18], we simulate hourly operations of ISCC- configured for solar-dispatching operation mode-, NGCC and CSP plants providing baseload generation. Our goal is to present a comprehensive view of how this technology compares to other sources of baseload power when two important metrics for policy makers and industry investors are considered: $\mathrm{LCOE}$ and the cost of $\mathrm{CO}_{2}$ abatement $(\mathrm{CoA})$. Different from previous studies our analysis uses the most up-to-date data and considers the effect of ambient temperature, solar resources, and a range of fuel prices that could be possible in the future. It also examines the dramatic effect that plausible changes in capital costs, tax incentives and capacity factors can have in the profitability of ISCC. We conclude that the ISCC is a cost effective way to harness solar power and reduce air emissions from electricity generation. Hence, although only a relatively small amount of solar capacity share (3\%-15\%) can be economically incorporated in an ISCC, including this technology in the several NGCC plants that may be built in the U.S. to replace coal-fired power plants is an alternative that should be seriously considered in regions with good solar resources.

\section{Method}

We consider an ISCC that integrates the most efficient NGCC and CSP technologies available in today's market, and estimate its LCOE, air-emissions, and CoA by simulating operations over one typical year in each of five possible U.S. locations. The ISCC is compared to a stand-alone NGCC and to a CSP with and without energy storage. A custom-made thermodynamic model of an ISCC plant composed of a 500-MW NGCC plant and a 50-MW solar field is developed to properly represent operations under different temperature and solar radiation conditions. Set in this way, the solar capacity share in the ISCC plant, which is defined in this paper as the ratio of CSP installed capacity to NGCC installed capacity, is $10 \%$ (i.e. 50MW of the CSP divided by $500 \mathrm{MW}$ of the NGCC). Depending on the location, this capacity will result in an annual solar electricity share (i.e. solar share of annual ISCC's electricity generation) of between 2.1 and $3.5 \%$. Typically, the CSP capacity share of the ISCC plants installed around the world does not exceed $15 \%$ of the total nameplate capacity [5]. This is consistent with previous studies that show this share minimizes the steam turbine efficiency reduction when solar-generated steam is not available [10,24]. Our analysis of the tradeoffs between capital and operating costs for different CSP capacity shares also confirms that $10 \%$ is an optimal choice (See SI section S.3.3).

The specifications of the NGCC plant (both the one integrated in the ISCC and the one examined as a stand-alone technology) are those of the GE FlexEfficiency-60 Combined Cycle power plant [19], while the solar component of the ISCC (i.e. solar field) is assumed to be identical to that of a CSP with parabolic trough solar collectors. Figure 1 presents a schematic of the ISCC analyzed in this paper.

Although other CSP technologies, such as the linear Fresnel lens and solar tower, could be used as the solar component of the ISCC [20], we choose a parabolic trough system because it is a technology widely deployed today with an installed capacity six times larger than other CSP technologies combined [21], has an excellent operating history of more than 30 years [3,21], and offers the most economical alternative for large power plant applications [22]. We assume the CSP (both the one integrated into the ISCC and the stand-alone CSP analyzed) is similar to the 64MW Nevada Solar One CSP Trough plant in Boulder city, NV [23]. 


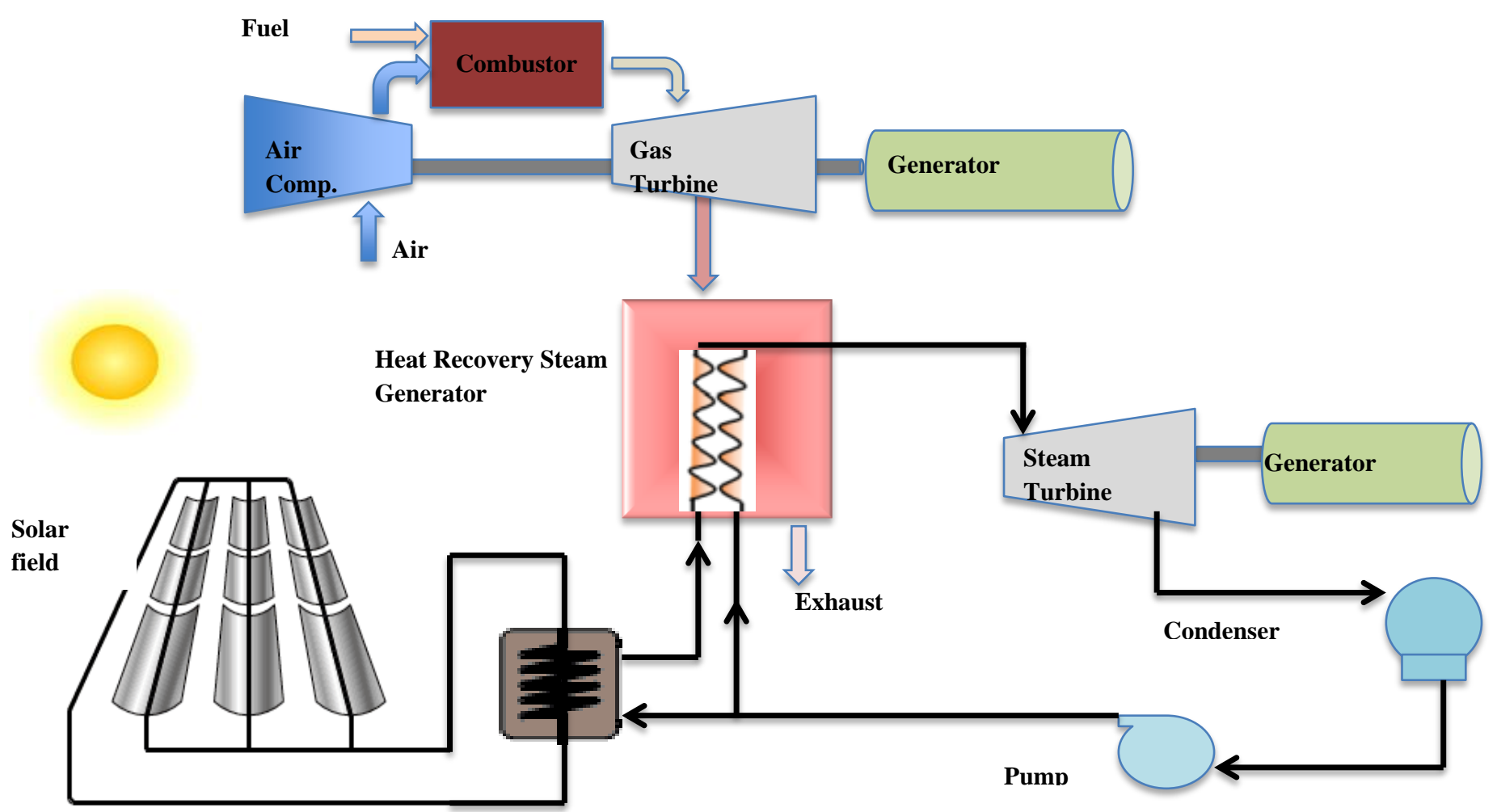

Figure 1. Diagram of an ISCC plant

\subsection{NGCC Assumptions}

Consistent with the GE specifications, the NGCC plant is assumed to achieve $61 \%$ efficiency in typical conditions when generating electricity at $80 \%$ of its nameplate capacity or more [19], a ramp rate of 50MW/min, a start-up time of less than 30 minutes, and an availability factor of $87 \%$ (see Supporting Information (SI) section S.1 for details on the NGCC model). The capital cost of a 500MW NGCC is assumed to be $917 \mathrm{k} \$ / \mathrm{MW}$ of net installed capacity while the fixed O\&M cost is estimated to be 13.1-14.91 $\mathrm{k} \$ \mathrm{MW}$ annually [25-27]. We assume a range of 4-18 \$/MMBtu for gas prices when calculating the LCOE and CoA, consistent with the AEO 2014 projections of natural gas prices rising from $\$ 4.52 /$ MMBtu in 2014 to $\$ 13.82 / \mathrm{MMBtu}$ in 2040 under the reference case, and to $\$ 8.65 / \mathrm{MMBtu}$ and $\$ 18.6 / \mathrm{MMBtu}$ in 2040 under the high and low oil and gas resources cases respectively [25].

\subsection{CSP Assumptions}

We assume the capital cost of the CSP is $4000 \$ / \mathrm{kW}$ (in 2012 US dollars) which is the actual cost of the recently completed Genesis Solar Energy Project in Blythe, California [21, 28] (See CSP modeling in SI section S.2 and sensitivity on capital costs in section 3.4.4). Having excellent solar resources and the optimal solar field size, the annual CSP plant capacity factor would be between 25\% and 30\% and the CSP plant would generate between 100 and 122 GWh/year [22, 24]. The analysis of a stand-alone CSP assumes placement in Las Vegas, NV. For the analysis of a CSP plant with energy storage (i.e. CSP+ES), we assume the CSP is coupled with a properly sized Molten Salt System (MSS) - a thermal energy storage technology commercially available at unit storage cost of $80 \$ / \mathrm{kWht}$ [23].

\subsection{ISCC Assumptions}

The ISCC power plant is assumed to operate in a dispatching mode where the solar steam generated by the CSP is augmented and expanded in the NGCC steam turbine to generate additional power. We choose to represent this mode of operation because of its economic and environmental advantages (see SI section S.3.4 for more details). The ISCC under 
this study is composed of two gas turbines (each one has $165 \mathrm{MWe}$ ), heat recovery steam generators (HRSGs) that produce steam at high pressure $(16,547 \mathrm{kPa})$, intermediate pressure $(2,482 \mathrm{kPa})$ and low pressure $(552 \mathrm{kPa})$, a steam turbine $(220 \mathrm{MWe})$, and a solar field $(50 \mathrm{MWe})$. The technical and economic parameters of the ISCC studied are summarized in Table 1.

The solar field is comprised of parallel rows of Solar Collector Assemblies (SCA) and requires an area of 255 acres, where 74 acres $\left(299,540 \mathrm{~m}^{2}\right)$ are used for the aperture reflective area (i.e. the area of the collector that reflects sunlight toward the receiver). SCAs supply thermal energy to produce steam to drive a steam turbine in a Rankine cycle with solar to thermal efficiency of $60.6 \%$. The concentration factor of solar radiation on the absorber is about 80 (calculated by dividing reflector area by focal area) [32], and the maximum temperature in the absorber is about $400{ }^{\circ} \mathrm{C}$. The solar field design-point adopted is based on an assumption of direct solar irradiance of $900 \mathrm{~W} / \mathrm{m}^{2}$ and air temperature of $25^{\circ} \mathrm{C}$. The parabolic trough plant is coupled to the high-pressure level in the HRSGs.

A thermodynamic model developed in MATLAB simulates plant operations by applying mass and energy balances to every component of the combined cycle and the parabolic trough collector field for different input data (see SI section S.1 and S.2). The model has been validated by comparing the NGCC simulation results with DOE/NETL cost and performance baseline estimates for NGCC plants [29] and also by comparing the CSP simulation results with NREL SAM model's output. The comparison of results is presented in the SI section S.3.2.

Table 1. ISCC plant's technical and economic parameters

\begin{tabular}{|l|l|}
\hline Parameter & Value ${ }^{30,31}$ \\
\hline $\begin{array}{l}\text { Overall gross plant capacity } \\
\text { (MW) }\end{array}$ & 550 \\
\hline Gas turbine capacity (MW) & 330 \\
\hline HRSG capacity (MW) & 220 \\
\hline Solar field capacity (MW) & 50 \\
\hline $\begin{array}{l}\text { Gas turbine isentropic efficiency } \\
(\%)\end{array}$ & $80-90(90)$ \\
\hline $\begin{array}{l}\text { Compressor isentropic } \\
\text { efficiency }(\%)\end{array}$ & $75-90(87.5)$ \\
\hline Gas turbine inlet temp. $\left({ }^{\circ} \mathrm{C}\right)$ & $1,280-1,400(1370)$ \\
\hline $\begin{array}{l}\text { Fuel higher heating value } \\
\text { (kJ/kg) }\end{array}$ & 52,288 \\
\hline $\begin{array}{l}\text { Air compressor outlet/inlet } \\
\text { pressure ratio }\end{array}$ & $1-25(18.5)$ \\
\hline $\begin{array}{l}\text { Steam turbine isentropic } \\
\text { efficiency }(\%)\end{array}$ & $80-90(85 \%)$ \\
\hline Steam turbine inlet temp. $\left({ }^{\circ} \mathrm{C}\right)$ & $280-600(570)$ \\
\hline $\begin{array}{l}\text { Steam turbine inlet pressure } \\
\text { (kPa) }\end{array}$ & $\begin{array}{l}12,755-17,237 \\
(16,547)\end{array}$ \\
\hline Boiler pressure (kPa) & 17,237 \\
\hline Boiler efficiency $(\%)$ & 80 \\
\hline Condenser pressure $(\mathrm{kPa})$ & $3.45-13.79(10.34)$ \\
\hline Condensate pump efficiency $(\%)$ & $75-90(80)$ \\
\hline Solar field outlet oil temp. $\left({ }^{\circ} \mathrm{C}\right)$ & 390 \\
\hline ISCC capacity factor $(\%)$ & 87 \\
\hline
\end{tabular}

\begin{tabular}{|l|l|}
\hline \multicolumn{1}{|c|}{ Parameter } & Value \\
\hline NGCC capital cost $(2012 \$ / \mathrm{kW})$ & $876-1050^{25-27}(917)$ \\
\hline NGCC O\&M fixed cost (2012\$/kW-yr) & $13.1-14.91^{25-27}(14)$ \\
\hline NGCC O\&M variable cost (2012\$/MWh) & $2-3.6^{25-27}(3)$ \\
\hline CSP capital cost (2012\$/kW) & $3000-5067^{25,32-34}(4000)$ \\
\hline CSP fixed O\&M cost (2012\$/kW-yr) & $60-67.26^{25,35}(65)$ \\
\hline Discount rate (before tax) (\%) & 7.5 \\
\hline Insurance rate (\%) & 0.5 \\
\hline Plant lifetime (years) & 25 \\
\hline Real bond interest rate (\%) & 5.83 \\
\hline Real preferred stock return (\%) & 5.34 \\
\hline Real common stock return (\%) & 8.74 \\
\hline Percent debt (\%) & 45 \\
\hline Percent equity “preferred stock” (\%) & 10 \\
\hline Percent equity “common stock” (\%) & 45 \\
\hline Federal tax rate (\%) & 34 \\
\hline State tax rate (\%) & 4.2 \\
\hline Property tax rate (\%) & 2 \\
\hline Inflation (\%) & 2.5 \\
\hline & \\
\hline
\end{tabular}

* Some parameters have a range of operating or estimated values. Values in parentheses are those used in all the base-case simulations

To properly account for varying solar resources (as measured by the Direct Normal Irradiance DNI) and temperature conditions likely to affect the performance of the CSP component, it is assumed that the ISCC plant could be located in one of five different locations in the U.S.; Barstow, CA; Honolulu, HI; Las Vegas, NV; San Antonio, TX; and San Diego, 
CA. Hourly solar radiation data and hourly temperature for a typical year for these sites has been obtained from the NREL System Advisor Model (SAM) database [23] which generates a typical year data file based on satellite-derived data over the period 1998-2005. The annual average solar energy resource (DNI) and temperatures for each site are summarized in Table 2.

Table 2. Descriptive statistics of solar resources and temperature for the typical year data reported in [23]

\begin{tabular}{|c|c|c|c|c|c|c|c|c|c|}
\hline \multirow[b]{2}{*}{ Location } & \multicolumn{3}{|c|}{ Solar Hours per day } & \multicolumn{3}{|c|}{ Direct Normal Irradiance } & \multicolumn{3}{|c|}{ Ambient Temp. $\left({ }^{\circ} \mathrm{C}\right)$} \\
\hline & $\begin{array}{l}\text { Annual } \\
\text { average }\end{array}$ & Range & $\begin{array}{l}\text { Standard } \\
\text { deviation }\end{array}$ & $\begin{array}{c}\text { Annual } \\
\text { average } \\
\left(\mathrm{kWh} / \mathrm{m}^{2}\right)\end{array}$ & $\begin{array}{c}\text { Daily } \\
\text { Range } \\
\left(\mathrm{W} / \mathrm{m}^{2}\right)\end{array}$ & $\begin{array}{c}\text { Standard } \\
\text { deviation } \\
\left(\mathrm{W} / \mathrm{m}^{2}\right)\end{array}$ & $\begin{array}{l}\text { Annual } \\
\text { average }\end{array}$ & Range & $\begin{array}{l}\text { Standard } \\
\text { deviation }\end{array}$ \\
\hline Barstow, CA & 9.3 & $0-13$ & 4.0 & 2981 & $0-1016$ & 395 & 20.1 & $1.2-41.9$ & 9.4 \\
\hline Honolulu, HI & 6.7 & $0-11$ & 3.0 & 2102 & $0-965$ & 326 & 23.7 & $9.6-26.4$ & 1.3 \\
\hline Las Vegas, CA & 8.8 & $0-13$ & 3.1 & 2802 & $0-1004$ & 387 & 18.9 & $-0.6-40.4$ & 9.7 \\
\hline San Antonio, TX & 5.4 & $0-11$ & 3.5 & 1714 & $0-964$ & 302 & 20.0 & $-1.6-38$ & 8.1 \\
\hline San Diego, CA & 6.7 & $0-12$ & 3.2 & 2082 & $0-951$ & 332 & 16.8 & $7.9-31.5$ & 4.0 \\
\hline
\end{tabular}

\subsection{Levelized Cost of Electricity (LCOE) Calculation}

$\mathrm{LCOE} \phi / \mathrm{kWh}$ for all the technologies considered in this study is estimated using eq. (1):

$L C O E=\frac{C C_{\text {annual }}+O \& M_{\text {annual }}+F C_{\text {annual }}}{E_{\text {annual }}}$

where

$C C_{\text {annual }}$ is the total annualized capital cost $(\$)$, obtained by multiplying the Capital Cost by the Fixed Charge Factor (FCF) which is a levelizing factor that depends on the expected life time of the investment and a number of financial variables. A Fixed Charge Factor (FCF) of 0.1128 (excluding any Investment Tax Credits) is assumed which is the default FCF used in [36]. This assumption is based on economic figures and equations explained in SI section S.1.3.

$O \& M_{\text {annual }}$ is the annual operational \& maintenance cost -both fixed and variable, excluding fuel costs-(\$)

$F C_{\text {annual }}$ is the annual fuel expenses (\$)

$E_{\text {annual }}$ is the annual electricity generation (MWh)

\subsection{Cost of Carbon Abatement (CoA) Calculation}

$\mathrm{CoA}$ in $\$$ tonne $\mathrm{CO}_{2}$ for a technology $k$ is estimated by using eq. (2):

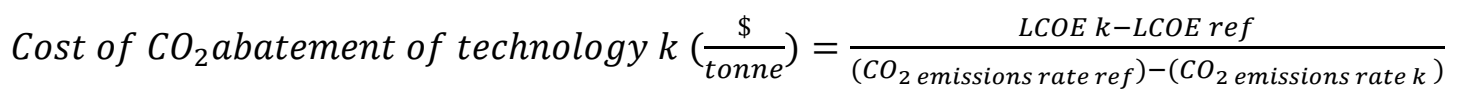

Where $\mathrm{CO}_{2}$ emissions rate $k$ is the rate at which $\mathrm{CO}_{2}$ is emitted by technology $\mathrm{k}$, expressed in tonnes/MWh, and $\mathrm{CO}_{2}$ emissions rate ref is the rate at which $\mathrm{CO}_{2}$ is emitted from a reference technology. The estimates of CoA in this study assume a reference $\mathrm{CO}_{2}$ emissions rate of 1950-2210 lb/MWh, which are the average emissions of coal-fired power plants observed in years 2007-2010 in the U.S. [37]. The LCOE of this reference technology LCOE ref is assumed to range between 2.5 (for an existing coal-fired power plant with no capital charges) and $5.6 \phi / \mathrm{kWh}$ (for a coal plant still paying its capital costs) [36]. Although there is uncertainty about the emissions of the plants that are or will be shutdown or ramped down during the operation of an ISCC (i.e. uncertainty about emissions displaced), estimating the CoA relative to an average coal plant offers useful information particularly for comparison with other carbon abatement alternatives. Also it is worth noting that, for the purpose of comparing the ISCC's CoA relative to other dispatchable 
technologies such as the NGCC or CSP+Storage, any choice of reference technology in the CoA estimation yields identical results.

\section{Results}

\subsection{Standalone Concentrated Solar Power (CSP)}

The levelized cost of electricity (LCOE) of a standalone CSP located in Las Vegas, Nevada is $20-23 \phi / \mathrm{kWh}$. If a $50 \mathrm{MW}$ CSP plant displaced the average U.S. coal-fired power plant in the US it would abate 103,487-117,285 tonnes of $\mathrm{CO}_{2}$ annually and the abatement of $\mathrm{CO}_{2}$ emissions would come at a cost of $150-215 \$ / \mathrm{CO}_{2}$ tonne. If instead of replacing a coal plant the CSP replaced the highly efficient NGCC considered in this study, then it would reduce carbon emissions by only 0.34-0.40 tonne/MWh, which combined with an assumption of NG prices in the range 4-18 \$/MMBTU, the range of the projected average NG prices under all AEO 2014 scenarios over the next 25 years, results in a $\mathrm{CO}_{2}$ abatement cost $\mathrm{CoA}$ of $270-480 \$ / \mathrm{CO}_{2}$.

\subsection{Concentrated Solar Power with Energy Storage (CSP+ES)}

The costs and performance of a CSP equipped with different sizes of MSS ranging from 2 to 18 hours of energy storage capacity located in Las Vegas, NV have been examined using the SAM model. In order to have a fully dispatchable CSP, the MSS should back up 300\% of the solar field nameplate capacity, which would increase the LCOE from 20.4 to 24.9 $\phi / \mathrm{kWh}$ and the corresponding $\mathrm{CO}_{2}$ abatement costs to 155-235 \$/tonne, assuming the emissions and LCOE of a reference plant equal to the average coal-fired power plant in the U.S.

\subsection{Standalone NGCC}

The LCOE ranges from 4.8 to $13.8 \notin / \mathrm{kWh}$ when natural gas prices range from 4-18 \$/MMBtu. Assuming the NGCC replaces a U.S. coal-fired power plant with average costs and emissions, its $\mathrm{CO}_{2}$ abatement cost is 40-200 \$/tonne. These LCOE estimates assume the plant operates at a capacity factor equal to its availability.

\subsection{Integrated Solar Combined Cycle (ISCC)}

Results show that an ISCC reduces the costs of harnessing solar power for electricity generation. Integrating the solar component of a conventional parabolic trough CSP plant into a NGCC leads to significant reductions in the capital cost and operating and maintenance costs due to utilization of common equipment such as the steam turbine, heat sink and balance of plant (BOP) and also to the elimination of thermal inefficiencies from daily start-up and shut-down of solar steam-turbine. NREL [24] has estimated the expected reduction in the capital and O\&M costs are about 28\% and 67\%, respectively. From our results we are able to estimate the reductions on capital and O\&M as reductions in LCOE. Comparing the levelized cost of solar electricity (LCOE-solar) of a $50 \mathrm{MW} \mathrm{CSP}$ integrated into a NGCC (i.e. in an ISCC) with the $50 \mathrm{MW}$ standalone CSP power plant described in section 2.2, we find that the LCOE-solar of the ISCC is $35-40 \%$ less than that of a standalone CSP. For example, the LCOE-solar of an ISCC at Barstow, CA is about 11.3 $\varnothing / \mathrm{kWh}$ while the LCOE of a standalone CSP is $19.1 \phi / \mathrm{kWh}$.

\subsubsection{ISCC efficiency reductions from partial loading during cloudy days and non-solar hours}

An ISCC configured for solar-dispatching operation mode has a steam turbine capable of handling all the steam generated by the NGCC as well as the steam generated by the solar field when operating at full capacity. Hence the steam turbine will operate away from its optimal design point during nights or cloudy days when the input stream from the solar field is diminished or absent. For the ISCC considered in this study, at non-solar hours, the steam turbine will operate at $77 \%$ of its capacity (i.e. $170 \mathrm{MW}$ out of its $220 \mathrm{MW}$ of nameplate capacity) which, according to the Bartlett equation [38], results in an efficiency reduction of $0.01 \%$ (see Appendix A-1.2). The reduction is taken into account by the thermodynamic model used to simulate ISCC performance. For example, for an ISCC in Las Vegas, the total annual electricity generation -in a "typical year"- is estimated to be $3,858 \mathrm{GWh} / \mathrm{yr}$ from which $125 \mathrm{GWh} / \mathrm{yr}$ are generated by the 
solar field. Thus, the solar generation contributes about $3,2 \%$ of the total electricity generated annually by the ISCC plant. Also, the electricity generation reduction in the steam turbine cycle due to inefficiencies that result from partial loading when the solar field goes off is $48.3 \mathrm{MWh} / \mathrm{yr}$.

\subsubsection{Impact of solar resources and ambient temperature on ISCC performance}

Figure 2(a) depicts the difference in LCOE between the ISCC and NGCC plants at the selected sites and for different assumptions about natural gas prices. It shows that sites with higher average DNI, ceteris-paribus, result in lower LCOE. At a natural gas price of $\$ 6 / \mathrm{MMBtu}$, the LCOE of an ISCC in Barstow, CA - the highest annual average DNI of the considered five sites at $2981 \mathrm{kWh} / \mathrm{m}^{2}$ - is $6.26 \phi / \mathrm{kWh}$, while the LCOE of an identical plant located in San Antonio, TX annual average DNI of $1714 \mathrm{kWh} / \mathrm{m}^{2}$ - is $6.36 \phi / \mathrm{kWh}$. The ambient temperature, on the other hand, has significant but conflicting impact on the two main components of the ISCC plant. While increasing the ambient temperature reduces the gas turbine efficiency, it boosts the solar field conversion efficiency. For the ISCC of this study, the percent reduction in gas turbine efficiency is lower than the percent increase in solar conversion efficiency; however, because of the small contribution of the solar field to the annual electricity generation at the ISCC, in general, higher average temperatures mean higher LCOEs. This is illustrated by the plants in Honolulu, HI $(6.34 \phi / \mathrm{kWh})$ and San Diego, CA $(6.31 \phi / \mathrm{kWh})$; two sites that almost have the same annual average DNI of $2080-2100 \mathrm{kWh} / \mathrm{m}^{2}$, but differing average ambient temperatures of $23.7^{\circ} \mathrm{C}$ and $16.8{ }^{\circ} \mathrm{C}$, respectively. Indeed, while the turbine cycle efficiency operating at Honolulu (23.7 ${ }^{\circ} \mathrm{C}$ ) is $0.69 \%$ lower than when operating at San Diego $\left(16.8{ }^{\circ} \mathrm{C}\right.$ ) (consistent with results reported by [39,40]), the electricity generation of the solar field at Honolulu is $1.4 \%$ higher. However, because the contribution of the solar field to the annual electricity generation at the ISCC plant is less than 3\%, a $1.4 \%$ increase in the electricity from the solar field results on just a $0.042 \%$ increase in total electricity generation.

While comparing LCOE gives information about the economic benefits of an ISCC under high natural gas prices, it fails to account for the ISCC's environmental superiority in reducing $\mathrm{CO}_{2}$ and other emissions. Figure 2(b) shows the CoA of an ISCC in the five considered locations and a NGCC, relative to the average U.S. coal-fired power plant. The figure shows the natural gas prices that are required for the ISCC and the NGCC to have identical CoA (i.e. the breakeven natural gas prices).

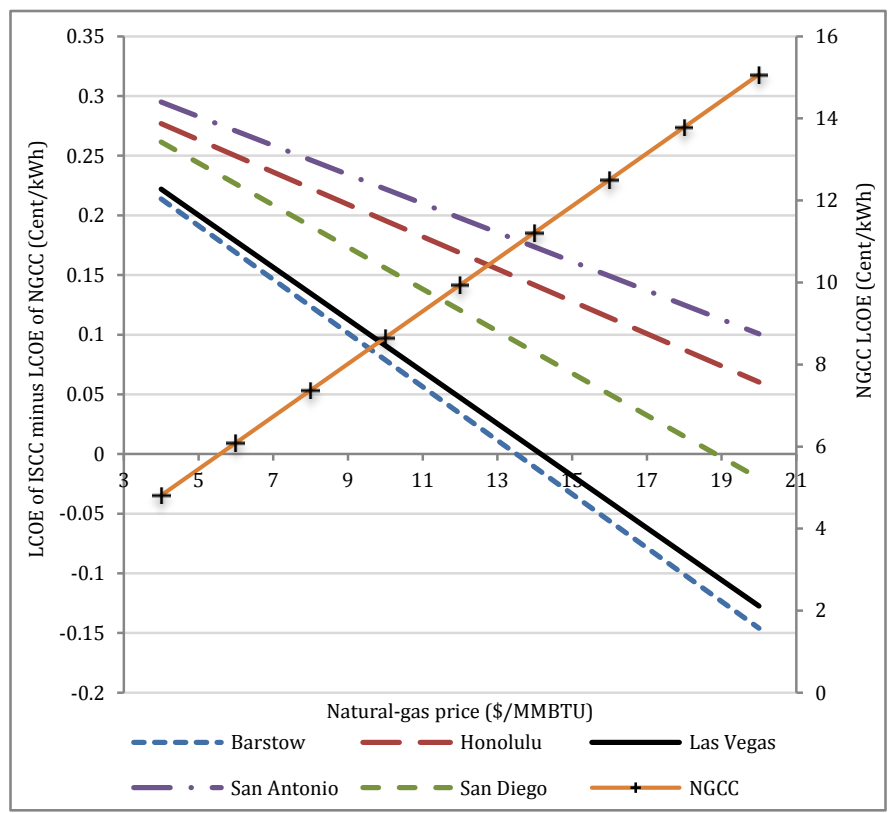

(a)

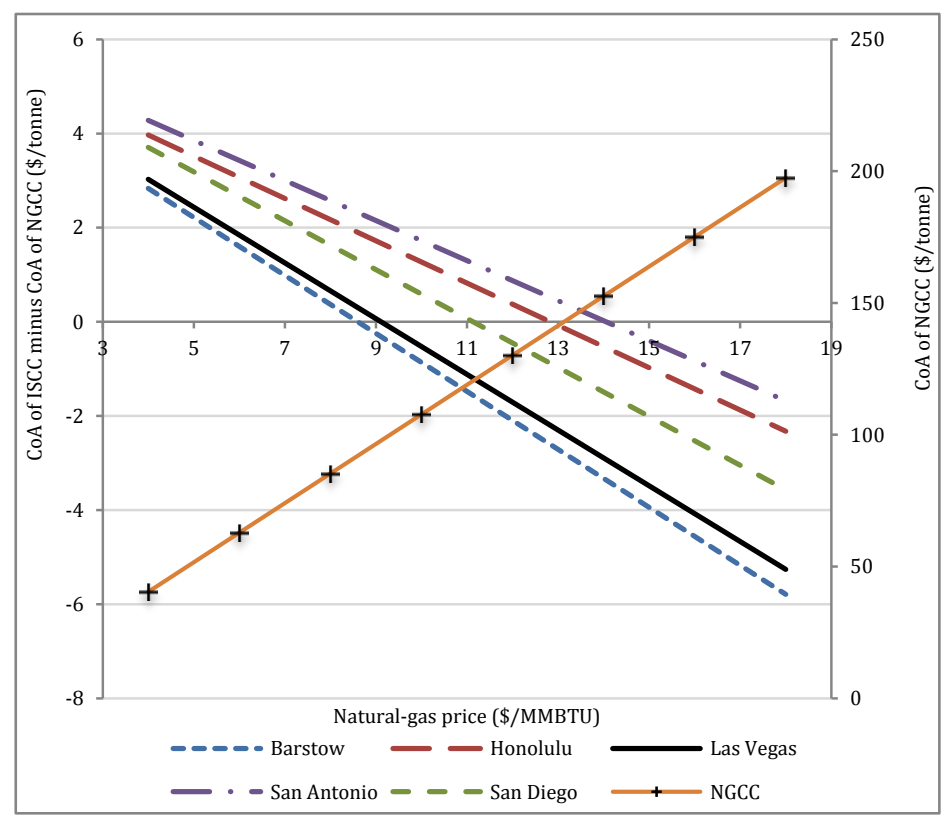

(b)

Figure 2. Differences in LCOE (a) and CoA (b) of 500 MW NGCC \& 550 MW ISCC Plants at different fuel prices (assumed constant over 25 years), and locations. The fuel price at which the difference in LCOE (or CoA) is zero, is the "break-even natural gas price" 
Interestingly, the breakeven $\mathrm{NG}$ prices found for $\mathrm{CoA}$ are much lower than those for LCOE. For example, while $\$ 13.5 / \mathrm{MMBtu}$ is the breakeven NG price for LCOE at Barstow, CA, just $\$ 8.5 / \mathrm{MMBtu}$ is the breakeven $\mathrm{NG}$ price for $\mathrm{CoA}$ at this location.

Another way to compare the ISCC and NGCC accounting for their differences in $\mathrm{CO}_{2}$ emissions is by assuming a carbon price. Figure 3 depicts the LCOE of ISCC at Las Vegas, NV, assuming carbon prices of $\$ 39$ and $\$ 53$ per tonne which are representative of the estimated social cost of carbon (SCC) in 2015, and of the average SCC over the years of 2015-2040 [41]. The figure also shows the effect of a $30 \%$ reduction in capital costs due to the Solar Investment Tax Credit (ITC) which provides investors with a $30 \%$ tax credit for installation expenses of qualifying renewable energy facilities including CSP plants installed by the end of 2016 .

\subsubsection{Effect of capacity factors in the comparison of LCOE and $\mathrm{CoA}$ of different technologies.}

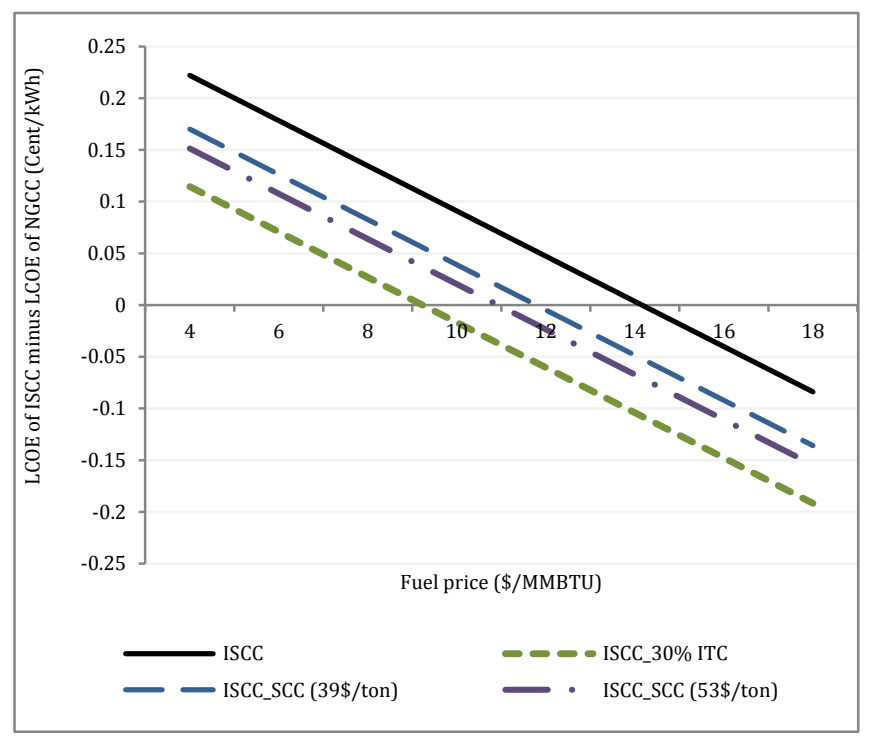

Figure 3. Difference in the LCOE of $550 \mathrm{MW}$ ISCC Plant and LCOE of 500 MW NGCC at Las Vegas, NV, under different fuel prices, carbon prices, with and without

So far, the LCOE estimates presented assume the plants operate at a capacity factor equal to their availability. This assumption fails to capture the fact that, instead of operating as baseload plants, they may be ramped up and down by an electricity system operator to balance electrical demand and supply. Made uniformly across the plants compared, this assumption does not affect their relative profitability, however, it ignores the fact that differences in marginal costs and operational flexibility will determine the ultimate dispatch order, affecting capacity factors and LCOE values. For example, a NGCC that is dispatched less than an ISCC, will have a lower capacity factor and hence, relatively higher LCOE values compared to the ISCC. In general, because of its zero marginal cost, a CSP with energy storage (ES) would be dispatched before a NGCC or ISCC. So for the purposes of estimating the relative LCOE and CoA costs, it is safe to assume that the capacity factor of the CSP+ES is equal to its availability. There is not a clear indication of the relative dispatch order between the NGCC and the ISCC. An accurate estimation of the capacity factor of the NGCC and ISCC in a power system requires simulation of balancing authority operations and/or electricity market outcomes using unit commitment/economic dispatch models [42] that properly account for the need to balance generation with time-varying electrical load, and for the costs and performance of all power generators when dispatched at different output levels.

To appreciate the difficulty of correctly inferring the relative capacity factors of the ISCC and NGCC without a proper modeling framework, it is useful to consider that given that the marginal costs of the NGCC are lower than those of the ISCC at non-solar hours, and higher during solar hours, one could conclude that in cases of lower electrical demand, the ISCC should operate during the day and shutdown at night when the NGCC can operate more efficiently. However, this conclusion may be wrong as it does not account for path-dependencies that are considered in a multi-period optimization framework. A cold start of the ISCC in the morning could offset the gains from reduced natural gas consumption during the day. It may be that the systems' costs over the full day period are minimized when the ISCC is kept operating at night even if its fuel efficiency is lower than that of the NGCC, because this avoids the morning start-up costs and takes advantage of the low marginal costs of the ISCC during solar hours.

To explore how the LCOE and CoA comparisons would change we consider higher and lower ISCC's capacity factor relative to a NGCC plant. We assume that the change in capacity factor does not affect the ISCC's efficiency but instead changes the amount of time it remains shutdown, affecting in the same proportion, its electrical output and operating variable costs. The results, as depicted in figures 4 (a) \& (b), show that the change in the capacity factor has a significant impact on the LCOE and CoA. As the capacity factor of the ISCC is $10 \%$ higher than the capacity factor of the NGCC, the CoA and LCOE of the ISCC are less than those of the NGCC for natural gas prices in the range considered (i.e. 4 $18 \$$ MMBTU). On the contrary, when the ISCC's annual capacity factor is lower than that of the NGCC by $10 \%$, the 
LCOE of the ISCC is higher than the LCOE of the NGCC for all natural gas prices in the range 4-18 \$/MMBTU, while the CoA of the ISCC is only lower than the CoA of the NGCC for gas prices that exceed $17 \$ / M M B t u$. If the capacity factor of ISCC is just 5\% higher than that of the NGCC, the breakeven gas prices for CoA and LCOE of the ISCC are about \$5.5/MMBtu and \$8/MMBtu, respectively.

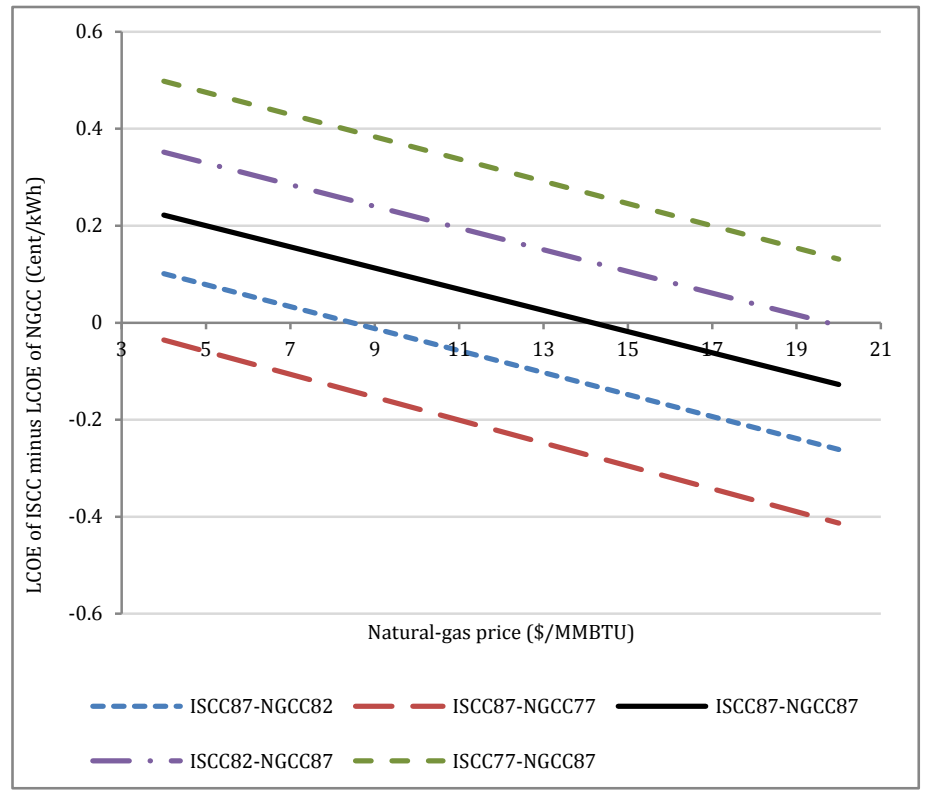

(a)

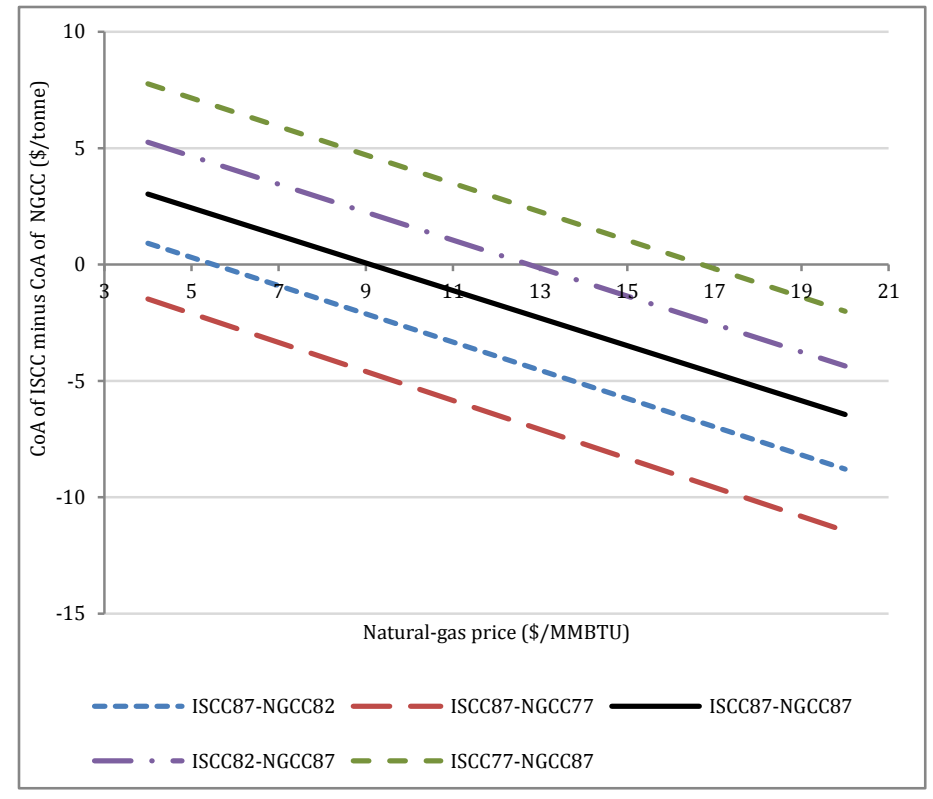

(b)

Figure 4. Difference in LCOE (a) and CoA (b) for 550 MW ISCC Plants and 500 MW NGCC at different capacity factors of ISCC and NGCC. The number after the plant type refers to capacity factor. For example, ISCC 87 refers to an ISCC operated at an $87 \%$ capacity factor

\subsubsection{Uncertainty on future capital costs of a CSP and its impact on relative LCOE and CoA estimates.}

Estimates of the capital costs of a CSP plant reported in the literature are between 3000 and $50672012 \$ / \mathrm{kWe}[25,28,32$ $34,43,44]$. IEA [33] estimates the capital cost of a CSP plant in 2014 to be around $4200 \$ / \mathrm{kW}$, decreasing to $3000 \$ / \mathrm{kW}$ by 2020. Similarly, a study published by the International Renewable Energy Agency (IRENA) in 2013 reported that the costs of installed parabolic trough systems were 3400-4600 $\$ / \mathrm{kW}$ for load factors of 20-27\% [34], and projected a 30$50 \%$ reduction in capital costs by 2020 due to technological learning and economies of scale following the increasing deployment of CSPs. This projection of capital cost reductions was also consistent with the ambitions of the SunShot Initiative, an aggressive R\&D plan launched by the U.S. DOE in 2011 [44], to make large-scale solar energy systems cost competitive (6 cents/kWh or less) without subsidies, by the end of the decade. This would have required a reduction of more than $50 \%$ in capital costs, estimated to be about $\$ 4,000 / \mathrm{kW}$ in early 2012 . However, during the last 4 years, the EIA estimates of capital costs reported in the Annual Energy Outlook reports (AEO) for a CSP have been significantly revised up and down, due to changes in both the forecast of deployment, and the expected cost reductions that would result from each unit of deployment. [45, 46].

To explore the effect that lower CSP costs would have on ISCC economics, figures 5 (a) \& (b) show how the breakeven NG price changes -from the LCOE and CoA perspectives- when the capital cost of a CSP is assumed to be on the low range of the capital cost estimates (i.e. $\$ 3000 / \mathrm{kWe)}$ ). At this lower CSP capital cost case, the LCOE of an ISCC located in places with excellent solar resources areas such as Barstow, CA and Las Vegas, NV is found to be $6.18 \phi / \mathrm{kWh}$ (at a natural gas price of $\$ 6 / \mathrm{MMBtu}$ ) compared with $6.26 \phi / \mathrm{kWh}$ in the base case (refer to section 3.4.2). Accordingly, the breakeven gas prices for CoA and LCOE of ISCC become about $\$ 6.5 / \mathrm{MMBtu}$ and \$10/MMBtu, respectively. In comparison, the breakeven gas prices for CoA and LCOE of ISCC in the base case are $\$ 8.5 / \mathrm{MMBtu}$ and $\$ 13.5 / \mathrm{MMBtu}$, respectively. 


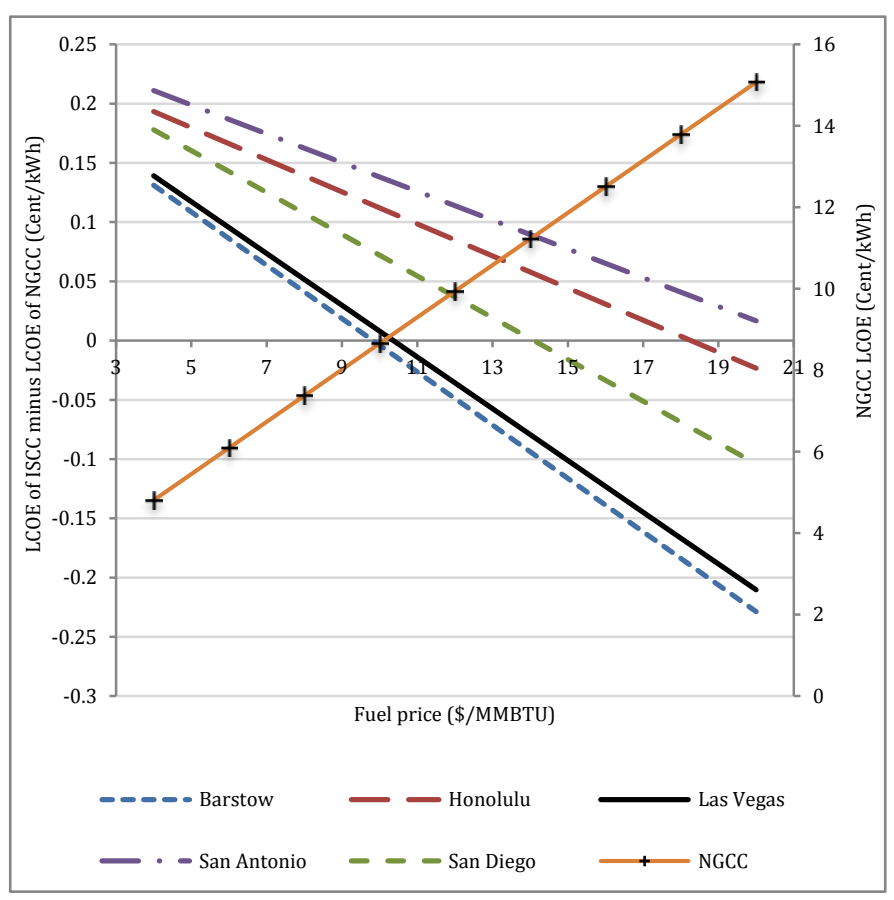

(a)

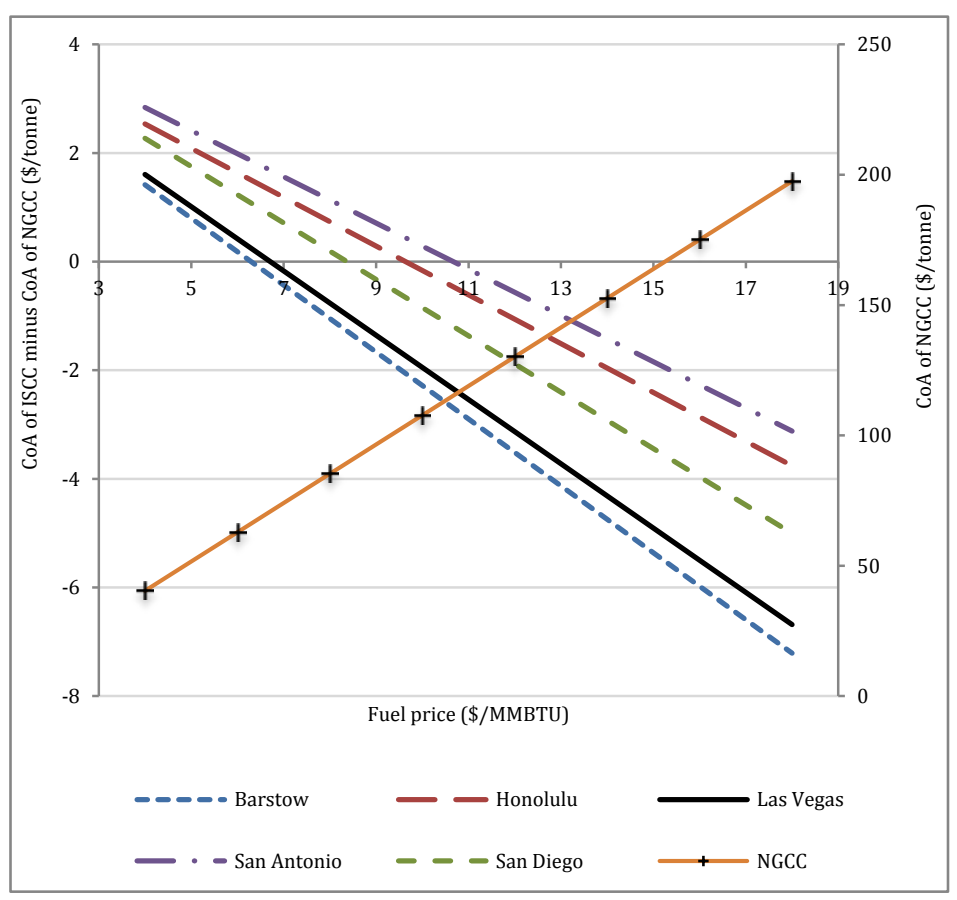

(b)

Figure 5. Differences in LCOE (a) and CoA (b) between 500 MW NGCC \& 550 MW ISCC Plants for different fuel prices and locations, assuming a CSP capital cost of $3000 \$ / \mathrm{kW}$

\section{Discussion}

Table 3 summarizes the comparison between NGCC, ISCC, CSP and CSP+ES technologies for the base-case assumptions on costs, capacity factors and emissions reported in section 2, and assuming they are all located at Las Vegas, NV. At current U.S. NG prices (below 4 \$MMBtu), assuming identical capacity factors, and in the absence of a carbon price, the ISCC is not cost competitive with a NGCC plant, so investors considering this technology must have other incentives such as the need to comply with Renewable Portfolio Standard (RPS) targets. Indeed, the most cost effective way to reduce the electricity costs of a CSP is by coupling it with a NGCC into an ISCC system. The levelized cost of electricity from a CSP that is part of an ISCC plant is 35\%-40\% lower than the LCOE of a stand-alone CSP. Also, the ISCC provides a modest hedge against high natural gas price fluctuations since the break-even natural gas price assuming excellent solar resources such as those in Barstow, CA and Las Vegas, NV varies between 13.5 \$/MMBtu and 14 \$MMBtu which are high values, but not implausible as it can be judged from the prices projected by EIA [25] under the Low Oil and Gas Resource Scenario.

Table 3. NGCC, ISCC, CSP and CSP+ES comparisons summary

\begin{tabular}{|c|c|c|c|c|c|c|c|}
\hline & \multicolumn{2}{|c|}{$\mathrm{NGCC}^{(\mathrm{i})}$} & \multicolumn{2}{|c|}{ ISCC $^{(i)}$} & \multirow{2}{*}{$\frac{\mathrm{CSP}^{(\mathrm{i})}}{\text { No storage }}$} & \multicolumn{2}{|c|}{$\mathrm{CSP}+\mathrm{ES}^{(\mathrm{ii})}$} \\
\hline & @ 4 \$/MMBtu & @ 18 \$/MMBtu & @ 4 \$/MMBtu & @ 18 \$/MMBtu & & 2 Hrs ES & 18 Hrs ES \\
\hline $\begin{array}{c}\text { Nameplate } \\
\text { Capacity (MW) }\end{array}$ & 500 & 500 & 550 & 550 & 50 & 50 & 50 \\
\hline $\begin{array}{c}\mathrm{LCOE}^{(\mathrm{iii})} \\
(\mathrm{Cent} / \mathrm{KWh}) \\
\end{array}$ & 4.8 & 13.8 & 5.0 & 13.7 & 19.94 & 20.42 & 24.9 \\
\hline $\operatorname{CoA}^{(\mathrm{iv})}$ (\$/ton) & 40 & 198 & 43 & 192 & 152 & 157 & 205 \\
\hline
\end{tabular}

(i) Base-case assumptions as reported in Table 1. (ii) Cost assumptions as reported in section 2.2. (iii) LCOE calculated as described in section 2.4. (iv)The CoA as described in section 2.5, assuming that these technologies are replacing a coal-fired power plant (with no capital charges) whose $\mathrm{LCOE}$ is $2.5 \phi / \mathrm{kWh}$, and $\mathrm{CO}_{2}$ emissions rate is $2080 \mathrm{lb} / \mathrm{MWh}$, which is the average emission rate of coal-fired power plants observed in years 2007 2010 in the U.S. [37] 
The advantages of an ISCC over a NGCC are clearer when $\mathrm{CO}_{2}$ emissions are considered. In a world where the goal is to reduce $\mathrm{CO}_{2}$ emissions at the lowest possible cost, an ISCC in Barstow would be more economic than a NGCC for natural gas prices above 8.5 \$/MMBtu. If the current scheme of the solar investment tax credit (ITC) [47], which provides a 30\% tax credit for projects that are placed in service prior to January 2017, was extended, the LCOE of the CSP and ISCC would be reduced by $25-28 \%$ and $3-4 \%$, respectively, which would make the ISCC more economical than a NGCC at fuel prices in the range 8.5-9.5 $\$ / \mathrm{MMBtu}$, even in the absence of a carbon price. (See a table of LCOE and CoA values in S.I. section S.4.)

\section{Conclusion}

This study provides a comparative assessment of the economic and carbon abatement advantages of ISCC plants, a technology that integrates solar thermal energy into efficient and widely installed natural gas combined cycle power plants. The benefits of integration include reduction in the capital and fixed and variable operations and maintenance costs resulting from shared equipment and personnel, and from CSP and NGCC efficiency improvements.

The analysis shows that the ISCC is a much better way to harness thermal solar electricity than a stand-alone CSP or a CSP with energy storage. However, under low and moderate natural gas prices and in the absence of carbon prices, capacity factor differences or subsidies, the NGCC generates electricity at lower costs. Considering a price for carbon emissions would significantly reduce the gap between ISCC and NGCC LCOEs and would make the breakeven gas price to be in the range of 10.5-12 \$/MMBtu at locations with excellent solar resources. Breakeven gas prices would be even lower, in the range 8.5-9.5 \$/MMBtu under the 30\% ITC program.

The ISCC environmental advantages can be further appreciated when looking at its ability to reduce the costs of carbon abatement. The CoA of an ISCC is lower than that of a CSP and NGCC in locations with good solar resources, when natural gas prices are 8.5-9 \$MMBtu. If the capacity factor of the ISCC were $10 \%$ higher than the capacity factor of a NGCC, then its CoA would be lower - even if natural gas is priced at $4 \$ \mathbf{M M B t u}$.

If the CSP capital costs were to go down to $\$ 3,000 / \mathrm{kW}$, a plausible event in the next decade, then the ISCC plant would be more competitive with a lower LCOE than a NGCC for gas prices in the range of 9.5-10.5 \$/MMBtu, even if there are no subsidies or carbon pricing. The CoA of the ISCC would be competitive for NG prices at 6.5 \$/MMBtu. Such breakeven gas prices could be much lower if CSP achieves higher capital cost reduction as expected by DOE, IEA and IRENA.

We conclude that although only a relatively small amount of solar capacity share (3\%-15\%) can be economically incorporated in an ISCC, deploying this technology in the several NGCC plants potentially built in the U.S. to replace coal-fired power plants is an alternative that should be seriously considered in regions with good solar resources. The results presented can be used by policy makers and investors in an analysis considering a diverse set of scenarios with differing future fuel prices, air emissions regulations, and power plant dispatch practices.

\section{Acknowledgements}

This work received financial support from the Saudi Aramco PhD Scholarship Program, and the Center for Climate and Energy Decision Making (SES-0949710) funded by the National Science Foundation. The authors express their sincere gratitude to Dr. Naif M. AlAbbadi from King Abdulaziz City for Science and Technology (KACST), Professors Richard Newell and Timothy L. Johnson from Duke University, and two anonymous reviewers who provided valuable feedback. 


\section{References}

[1] T. B. Johansson, H. Kelly, A. K. N. Reddy, and R. H. Williams. Renewable energy, sources for fuels and electricity. Washington DC: Island Press; Chapter 5; 1993; p. 234-6.

[2] P. Schwarzbözl, R. Buck, C. Sugarmen, A. Ring, M.J. Marcos, P. Altwegg, J. Enrile. Solar gas turbine systems: design, cost and perspectives. Solar Energy 80 (2006).

[3] National Renewable Energy Laboratory. Assessment of Parabolic Trough and Power Tower Solar Technology Cost and Performance Forecasts. Report prepared by Sargent \& Lundy LLC Consulting Group, 2010.

[4] C. Bohtz, S. Gokarn, E. Conte. Integrated Solar Combined Cycles (ISCC) to Meet Renewable Targets and Reduce CO2 Emissions. Power Gen Europe Conference, Austria (2013).

[5] O. Behar, A. Kellaf, K. Mohamedi, S. Ait-Kaci. A Review Of Integrated Solar Combined Cycle System (ISCCS) With A Parabolic Trough Technology. Renewable and Sustainable Energy Reviews 2014; 39: 223-50.

[6]. J. Peterseim, S. White, A. Tadros, and U. Hellwig. Concentrated solar power hybrid plants, which technologies are best suited for hybridisation?. Renewable Energy 2013; 57: 520-32.

[7] M.A.H. El-Sayed. Solar supported steam production for power generation in Egypt. Energy Policy 2005; 33: 1251-9.

[8] J. Antonanzas, E. Jimenez, J. Blanco, F. Antonanzas-Torres. Potential Solar Thermal Integration in Spanish Combined Cycle Gas Turbines. Renewable and Sustainable Energy Reviews 2014; 37: 36-46.

[9] O. Behar, A. Kellaf, K. Mohamedi, M. Belhamel. Instantaneous performance of the first integrated solar combined cycle system in Algeria. Energy Procedia 2011; 6: 185-93.

[10] B. Kelly, U. Herrmann, M.J. Hale. Optimization studies for integrated solar combined cycle systems. Proceedings of Solar Forum 2001 Solar Energy: The Power to Choose; Washington, DC; April 21-25, 2001.

[11] A. Rovira, M.J. Montes, F. Varela, M. Gil. Comparison of heat transfer fluid and direct steam generation technologies for integrated solar combined cycles. Applied Therm. Eng. 2013; 52: 264-74.

[12] M.J. Montes, A. Rovira, M. Muñoz, J.M. Martínez-Val. Performance analysis of an Integrated Solar Combined Cycle using Direct Steam Generation in parabolic trough collectors. Applied Energy 2011; 88: 3228-38.

[13] H. Nezammahalleh, F. Farhadi, M. Tanhaemami. Conceptual design and techno-economic assessment of Integrated Solar Combined Cycle System with DSG technology. Sol. Energy 2010; 84: 1696-705.

[14] Yuanyuan Li, Yongping Yang. Thermodynamic analysis of a novel integrated solar combined cycle. Applied Energy 2014; 122: $133-42$.

[15] Esmail M.A. Mokheimer, Yousef N. Dabwan, Mohamed A. Habib, Syed A.M. Said, Fahad A. Al-Sulaiman. Development and assessment of integrating parabolic trough collectors with steam generation side of gas turbine cogeneration systems in Saudi Arabia. Applied Energy 2015; 141: 131-42.

[16] J. Antonanzas, M. Alia-Martinez, F. Martinez-de-Pison, F. Antonanzas-Torres. Towards the hybridization of gas-fired power plants: A case study of Algeria. Renewable and Sustainable Energy Reviews 2015; 51: 116-24.

[17] J. Dersch, M. Geyer, U. Herrmann, S. Jones, B. Kelly, R. Kistner, W. Ortmanns, R. Pitz-Paal, \& H. Price (2004). Solar Trough Integration into Combined Cycle Systems. ASME International Solar Energy Conference, June 15-20, 2002, Reno, Nevada.

[18] Jared Moore and Jay Apt. Can Hybrid Solar-Fossil Power Plants Mitigate CO2 at Lower Cost than PV or CSP?. Environ. Sci. Technol. 2013; 47: 2487-93.

[19] http://www.ge-

energy.com/products_and_services/products/gas_turbines_heavy_duty/flexefficiency_50_combined_cycle_power_plant.jsp.

Accessed on January 30, 2016. 
[20] D. Ugolini, J. Zachary, J. Park. Options for Hybrid Solar and Conventional Fossil Plants. Bechtel White Paper, Bechtel Technology, December 2009.

[21] National Renewable Energy Laboratory, Concentrating Solar $\quad$ Power Projects, http://www.nrel.gov/csp/solarpaces/by_project.cfm.

[22] The International Renewable Energy Agency (IRENA). Renewable Energy Technologies: Cost Analysis Series. IRENA Working Group; Volume 1: Power Sector; 2012.

[23] NREL SAM database, Last Accessed: January 30, 2016, http://maps.nrel.gov/node/10/.

[24] Price, H., Keamey, D.. Reducing the Cost of Energy from Parabolic Trough Solar Power Plants, International Solar Energy Conference; Hawaii; 2003.

[25] Energy Information Administration. 2014 Annual Energy Outlook report. Washington DC; 2014.

[26] Brattle Group. Exploring Natural Gas and Renewables in ERCOT, Part III, Prepared for The Texas Clean Energy Coalition. Filed May 29, 2014.

[27] The Northwest Power and Conservation Council (NPCC). Sixth Northwest Conservation And Electric Power Plan. 2013 revision.

[28] Genesis Solar Energy Project Datasheet. November 2010. http://www.doi.gov/news/pressreleases/upload/Genesis-Fact-Sheet20101104.pdf. Accessed January 30, 2016.

[29] NETL. Cost and Performance Baseline For Fossil Energy Plants Volume 1: Bituminous Coal And Natural Gas To Electricity. DOE/2010/1397; Revision 2a; September 2013.

[30] M.P. Boyce. Handbook for Cogeneration and Combined Cycle Power Plants. 2nd edition; ASME Press; 2010.

[31] Michael J. Moran and Howard N. Shapiro. Fundamentals of Engineering Thermo-dynamics. 4th Edition; Toronto; 2000.

[32] K. Ardani, R. Margolis. 2010 Solar Technologies Market Trends Report, prepared for U.S. Department of Energy. 2011.

[33] International Energy Agency (IEA). Technology Roadmap-Solar Thermal Electricity. 2014.

[34] EurObserv'ER. Solar Thermal and Concentrated Solar Power Barometer. May 2014.

[35] T. Bruckner et al. 2011: Annex III: Cost Table. In IPCC Special Report on Renewable Energy Sources and Climate Change Mitigation. Cambridge University Press; Cambridge, United Kingdom and New York, NY, USA; 2011.

[36] Integrated Environmental Control Model (IECM V8.0.2), Carnegie Mellon University, http://www.iecm-online.com/ Accessed October 21,2014. This is the public release of this model as of the access date.

[37] U.S. Environmental Protection Agency. The Emissions \& Generation Resource Integrated Database (eGRID). Last accessed: January 30, 2016, http://www.epa.gov/cleanenergy/energy-resources/egrid/ .

[38] R. L. Bartlett. Steam Turbine Performance and Economics. McGraw-Hill, New York, USA; 1958; pp. 70-109. LCCCN: 588039.

[39] F.R.P. Arrieta, E.E.S. Lora. Influence of ambient temperature on combined-cycle power-plant performance, Applied Energy 2005; 80: 261-72.

[40] H.H. Erdem, S.H. Sevilgen. Case study: Effect of ambient temperature on the electricity production and fuel consumption of a simple cycle gas turbine in Turkey. Applied Thermal Engineering 2006; 26: 320-6.

[41] Interagency Working Group on Social Cost of Carbon. Technical support document: Social cost of carbon for regulatory impact analysis under Executive Order 12866. White House, Washington, DC; 2013; http://1.usa.gov/18ftAsH. Accessed February 01, 2016.

[42] E. Ela, M. Milligan, A. Bloom, A. Botterud, A. Townsend, and T. Levin. Evolution of Wholesale Electricity Market Design with Increasing Levels of Renewable Generation. Technical Report NREL/TP-5D00-61765; September 2014. 
[43] Brett Prior. Concentrating Solar Power 2011: Technology, Cost and Markets. Greentech Media (GTM); 2011. http://www.gtmresearch.com/report/concentrating-solar-power-2011-technology costs-and-markets, Accessed December 92014.

[44] Department of Energy. SunShot Vision Study. Chapter 5: Concentrating Solar Power: Technologies, Cost, and Performance. February 2012.

[45] Energy Information Administration. Updated Capital Cost Estimates for Utility Scale Electricity Generating Plants. Washington, DC; April 2013

[46] Energy Information Administration. Updated Capital Cost Estimates for Electricity Generation Plants. Washington, DC; November 2010.

[47] S.J. Wagner, E.S. Rubin. Economic implication of thermal energy storage for concentrated solar thermal power. Renewable Energy 2012; 61: 81-95.

[48] J. Duffie and W. Beckman. Solar Engineering of Thermal Processes. John Wiley and Sons, Hoboken; New Jersey, USA; ${ }^{\text {rd }}$ edition; 2006.

[49] Fichtner Carbon Management GmbH. Methodology for conversion of a Combined Cycle Power Plant to an Integrated Solar Combined Cycle (ISCC): CDM Approved baseline and monitoring methodology AM0100. November 2011. 
Integrated Solar Combined Cycle Power Plants: Paving the Way for Thermal Solar Bandar Alqahtani and Dalia Patiño-Echeverri

\section{Graphical Abstract}
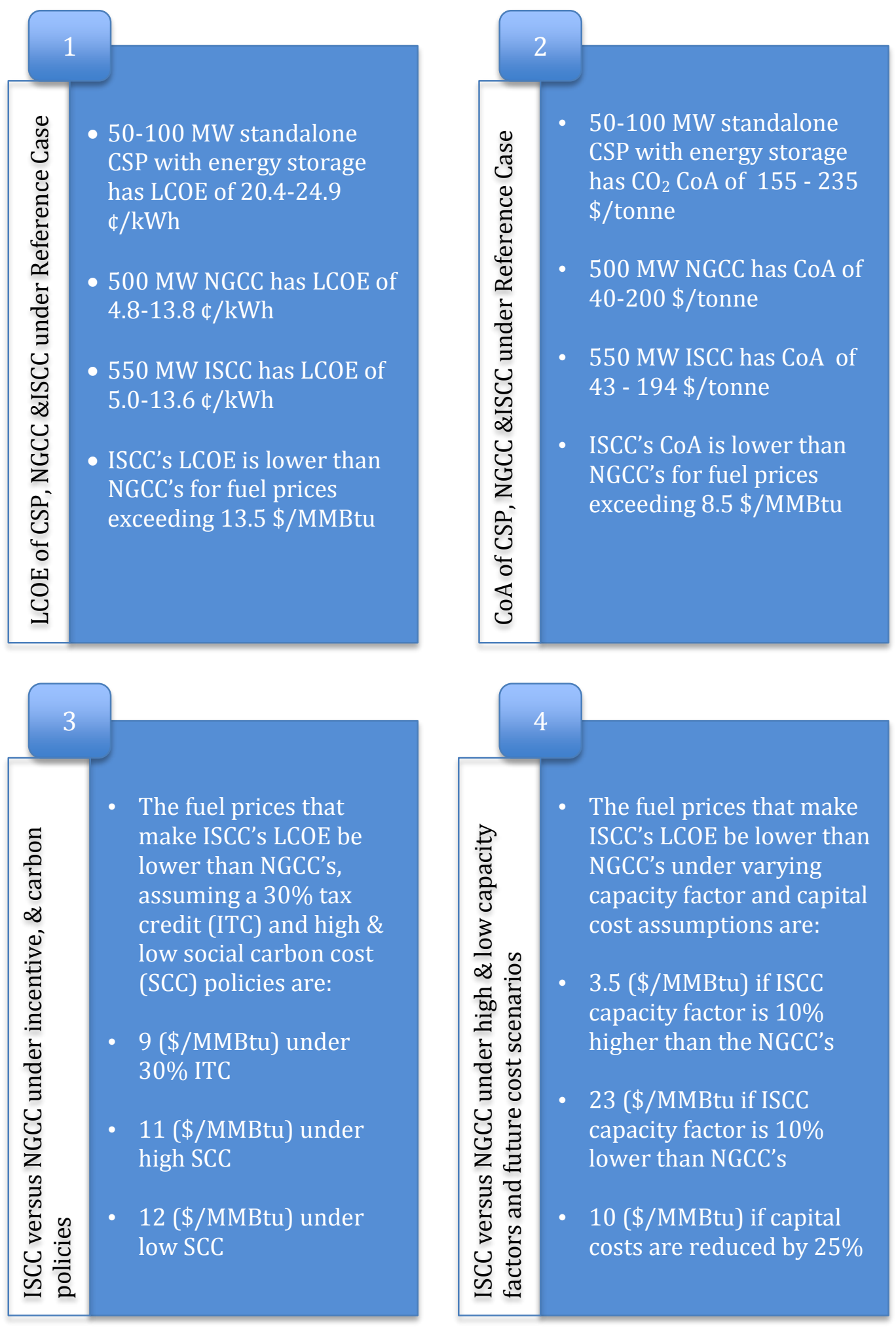